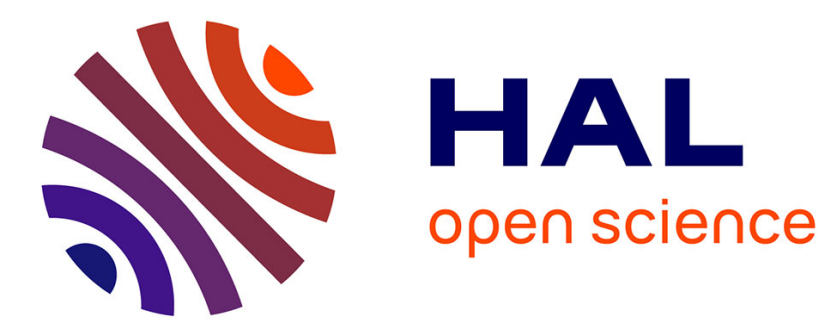

\title{
On-line thermocycles measurements in laser applications
}

\author{
I. Smurov, V. Martino, M. Ignatiev, G. Flamant
}

\section{To cite this version:}

I. Smurov, V. Martino, M. Ignatiev, G. Flamant. On-line thermocycles measurements in laser applications. Journal de Physique IV Proceedings, 1994, 04 (C4), pp.C4-147-C4-150. 10.1051/jp4:1994432 . jpa-00252695

\section{HAL Id: jpa-00252695 https://hal.science/jpa-00252695}

Submitted on 1 Jan 1994

HAL is a multi-disciplinary open access archive for the deposit and dissemination of scientific research documents, whether they are published or not. The documents may come from teaching and research institutions in France or abroad, or from public or private research centers.
L'archive ouverte pluridisciplinaire HAL, est destinée au dépôt et à la diffusion de documents scientifiques de niveau recherche, publiés ou non, émanant des établissements d'enseignement et de recherche français ou étrangers, des laboratoires publics ou privés. 


\title{
On-line thermocycles measurements in laser applications
}

\author{
I. SMUROV, V. MARTINO, M. IGNATIEV* ${ }^{*}$ and G. FLAMANT ${ }^{* *}$
}

Ecole Nationale d'Ingénieurs de Saint-Etienne, 58 rue Jean Parot, 42023 Saint-Etienne cedex 2, France

* Baikov's Institute of Metallurgy, Russian Academy of Sciences, Leninsky Prospect 49, 117911 Moscow, Russia

${ }^{* *}$ Institut de Science et de Génie des Matériaux et Procédés, CNRS, BP. 5, Odeillo, 66125 Font-Romeu cedex, France

\begin{abstract}
The thermal state of material in the zone of laser action is one of the main integrated parameters to determine the evolution of physicochemical processes and structural phase transformations. The conditions of temperature measurements in laser machining are among the most severe even for noncontact technique of optical pyrometry. From a general point of view, the absence of on-line control and monitoring is one of the main limitations of laser technology integration into modern industry. Data on surface temperature dynamics obtained by pyrometry could be widely used to: (a) understand and optimize the laser processes (i.e. define of the links between surface temperature history and the properties of treated materials); (b) create process control on-line including feedback from a pyrometer.

The main technical parameters of high speed pyrometer (HSP) are the following: brightness temperature range $1150 \mathrm{~K}(1550 \mathrm{~K})-3500 \mathrm{~K}$ (threshold sensitivity depends on selected wavelength); error of measurement $1 \%$; response time $190 \mu \mathrm{s} ; 200 \mu \mathrm{m}$ spatial resolution at $350 \mathrm{~mm}$ distance of pyrometer from the zone of temperature measurements; wavelength variation in 2 colour channels from 0.5 to $1.1 \mu \mathrm{m}$. The opportunities of actual temperature measurements by high speed high spatial resolution pyrometer system in wide range of laser applications are illustrated by : heat treatment, welding, cladding, and pulsed action.
\end{abstract}

\section{INTRODUCTION}

A number of methods can be used for real-time diagnostic of laser action: control of weld quality by acoustic emission, recording of stress pulses and thermally generated elastic waves during laser irradiation, etc. Among the optical methods, the following ones can be mentioned: on-line photo diode monitoring of $\mathrm{CO}_{2}$-laser welding, monitoring of pulsed laser melting and evaporation by means of measurements of deflection of secondary diagnostic laser beam, measurement of UV-plasma radiation during laser cutting of ceramics, timeresolved reflectivity, pool shape visualization, etc.

The process monitoring based on real physical variables (as, for example, surface temperature) and on indirect integrated parameters (signals connected with simultaneous variation of a number of physical variables, for example, total radiation intensity from the zone of laser action that is affected by both laser plume and surface temperature, which can not be easily separated) must be distinguished. Generally speaking, the optimization and online control based on indirect parameters monitoring are not universal and they may be used within limited range of process parameters.

\section{PYROMETER DEVELOPMENT AND EXAMINATION}

The development of pyrometer system for recording the actual surface temperature during laser machining involves significant methodological difficulties, that are determined by the following process parameters: wide temperature range $(800-4000 \mathrm{~K})$, high heating and cooling rates $\left(10^{3}-10^{6} \mathrm{~K} / \mathrm{s}\right)$, small size of heated zone $(1-3 \mathrm{~mm})$, influence of laser plume radiation, sharp variation of material's optical and thermal properties, etc.

To satisfy these requirements, the following basis of optic and electronic design was selected. The radiation from the heated surface of a sample passing through the photo and 
objective lenses, strikes upon the mirror with pin-hole diaphragm. After the diaphragm the light beam is dispersed by diffraction grating. Two silicon photo diodes are used to detect the surface radiation at selected wavelengths. The variations of the later (from 0.5 to $1.1 \mu \mathrm{m}$ ) are obtained by moving the photo diodes along the grating image plane. The wide temperature range of pyrometer was obtained by calculating the logarithm of the photo detectors signals. The analog processor forms the output signal which is proportional to brightness or colour temperatures $\left(1 \mathrm{mV}\right.$ per $\left.1^{\circ}\right)$. The output signal is recorded by means of data acquisition system directly into computer memory.

The main tasks of HSP trials were : (a) to check up the calibration linearity; (b) to demonstrate the main performance data (threshold sensitivity, noise, response time, spatial resolution). The threshold sensitivity is $1515 \mathrm{~K}$ for $\lambda_{1}=0.656 \mu \mathrm{m}$, and $1124 \mathrm{~K}$ for $\lambda_{2}=0.956 \mu \mathrm{m}$. The accuracy of pyrometer near the lower temperature level is $10 \mathrm{~K}$, and $5 \mathrm{~K}$ for wavelengths $\lambda_{1}=0.656 \mu \mathrm{m}$, and $\lambda_{2}=0.956 \mu \mathrm{m}$, respectively. The noise amplitude does not exceed $0.15 \%$. The examination of HSP have shown a good linearity at temperatures up to $2350 \mathrm{~K}$. At higher temperatures, the calibration curve can be extrapolated by Wien approximation up to $3500 \mathrm{~K}$.

\section{RESULTS AND DISCUSSION}

The temperature measurement method includes: recording the emission spectrum from erosion laser plasma (plume), determination of the spectral transparency windows, reflectometry with the auxiliary laser in the region of relative transparency, determination of the monochromatic emissivities $\varepsilon(\lambda=$ const, $T)$, measurement of the brightness temperatures and (or) colour temperature and recalculation of the true temperature.

3. 1. HARDENING. The thermocycles during $\mathrm{CO}_{2}$-laser hardening were investigated at fluent decrease of the beam traverse speed (BTS) from $4000 \mathrm{~mm} / \mathrm{min}$ to $400 \mathrm{~mm} / \mathrm{min}$. The sharp change of thermocycles characteristics for mild steel was found at shielding gas flow rate less than $35 \mathrm{l} / \mathrm{min}$. When BTS was more than $3100 \mathrm{~mm} / \mathrm{min}$ (laser power $1.7 \mathrm{~kW}$ ) the surface temperature was smaller than the threshold sensitivity $(1150 \mathrm{~K})$ for the selected wavelength. If BTS value was $15-25 \mathrm{~mm} / \mathrm{min}$ less, two situations were observed: in the first case, only upper part of the heating curve from $1150 \mathrm{~K}$ to $1350 \mathrm{~K}$ can be seen (Figure 1 , curve 3 ); in the second case, small variation of beam traverse speed (nearly 10 $\mathrm{mm} / \mathrm{min}$ ) led to sharp increase of heating (for example, curve 2 Figure 1). The maximum temperature variations were nonpredictable over the range 1400-1700 $\mathrm{K}$. These abrupt changes of thermocycles were measured at exactly the same parameters of the processes. When BTS was decreased more than $100 \mathrm{~mm} / \mathrm{min}$ the intensive melting of steel surface started (Figure 1, curve 1, "shelve" at the level of the steel melting point 1810K). The fluent transition between these two situations: first $T_{\max }$ about $1350 \mathrm{~K}$, second $T_{\max }$ about melting point was not observed. Such threshold type of thermocycles variation can be explained by the influence of surface oxidation on absorption coefficient.

It was possible to reduce the sharp influence of surface oxidation on thermocycles variation at high BTS and shielding gas flow rate larger than $35 \mathrm{l} / \mathrm{min}$. In this case, one type of thermocycles was observed with fair increase of maximum temperature at BTS range from 3350 to $3100 \mathrm{~mm} / \mathrm{min}$ (Figure 2, curve 3,2). When BTS was decreased up to 1300 $\mathrm{mm} / \mathrm{min}$ (with simultaneous decrease of laser power to $0.8 \mathrm{~kW}$, but with the same shielding gas flow rate) the fast heating and melting of the mild steel surface can be observed (Figure 2 , curve 1 ) as a result of the surface oxidation that was reinitiated.

3.2. WELDING. The deep penetration $\mathrm{CO}_{2}$-laser welding of mild steel plates (thickness 3,6 and $9 \mathrm{~mm}$ ) was investigated. The real-time thermocycle was measured just on the border of weld seam. The temperature signal is characterized by intensive "noise" due to metal droplets expulsion from the melt. The droplets temperature may be or lower, or higher than the welded seam in selected point. It depends whether the droplets crossed the pyrometers field of view on the final part of their trajectories (that is why the droplets temperature is relatively "cold"), or in the initial part of the trajectory, just after they have left the molten pool ("hot" droplets). The "noise" of typical temperature signal may be eliminated by a signal filtering technique without losing of useful information. On the other hand, "noise" frequency and amplitude also depend on process parameters: BTS, laser power, 


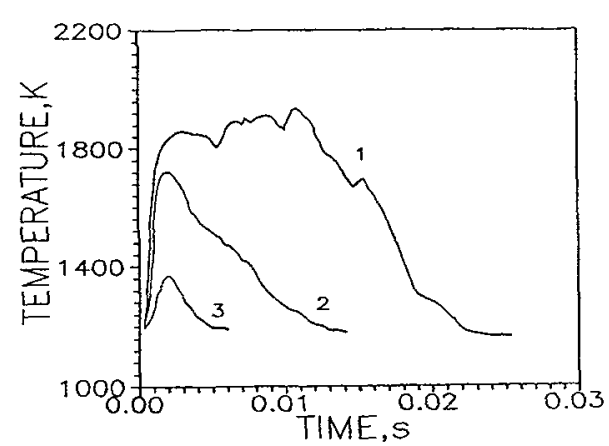

Fig.1. Surface temperature in the centre of the laser beam scan. Mild steel. Laser power $1.7 \mathrm{~kW}$. Beam traverse speed $(\mathrm{mm} / \mathrm{min})$ : curve 1 - 900; 2 - 3075; 3 3085. Shielding gas flow rate $28 \mathrm{l} / \mathrm{min}$.

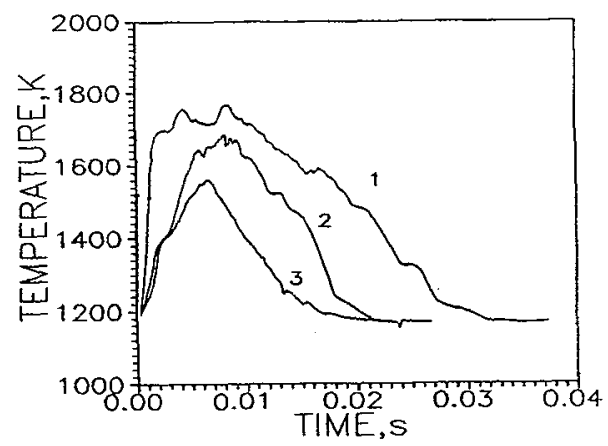

Fig.2. Surface thermocycles in the centre of the laser beam scan. Mild steel. Laser power : curve $1-0.8 \mathrm{~kW} ; 2,3-1.7 \mathrm{~kW}$. Beam traverse speed $(\mathrm{mm} / \mathrm{min})$ : curve 1 $1300 ; 2$ - 3100; 3 - 3350. Shielding gas flow rate $35 \mathrm{l} / \mathrm{min}$.

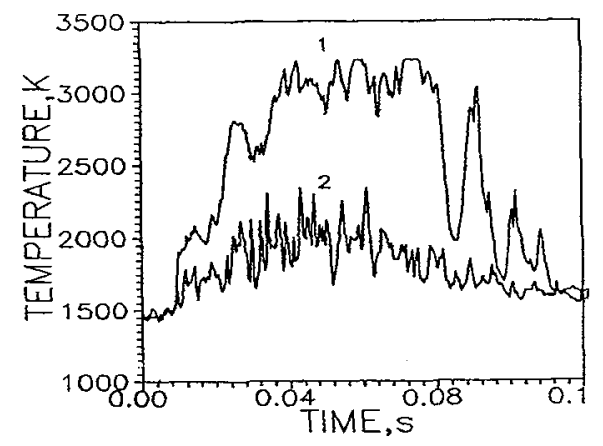

Fig.3. Pyrometer output signal for laser welding of $3 \mathrm{~mm}$ thickness mild steel plate. Laser power $5 \mathrm{~kW}$. Beam traverse speed (mm/min) : curve $1-2500 ; 2-4000$. Distance from the weld-seam axis $(\mathrm{mm})$ : curve $1-0.5 ; 2$ - 0.3 .

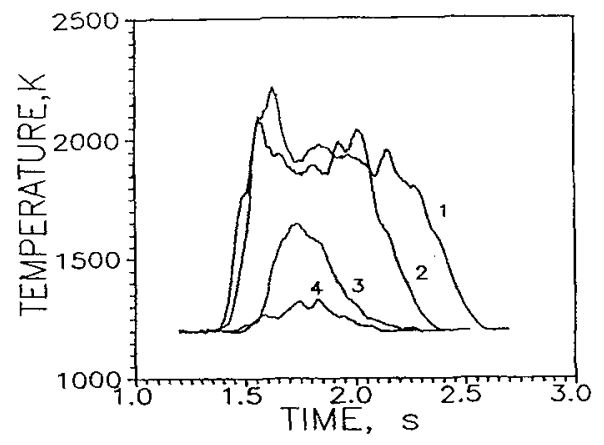

Fig.4. Thermocycles for laser cladding process. Laser power $1.9 \mathrm{~kW}$. Beam traverse speed $300 \mathrm{~mm} / \mathrm{min}$. Scanning beam parameters : frequency $400 \mathrm{~Hz}$; scanning width $3.0 \mathrm{~mm}$. Distance from the centre of laser beam scan $(\mathrm{mm})$ : curve 1 - $0 ; 2-1.4 ; 3-1.6 ; 4-1.8$.
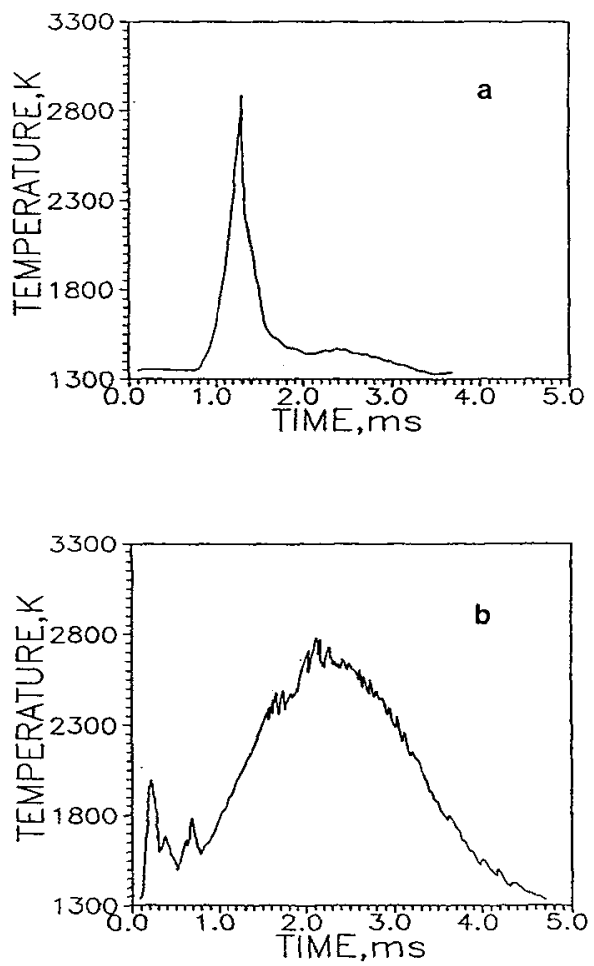

Fig.5. Surface thermocycles in the centre of laser spot for system "Mo coating on $\mathrm{Fe}$ substrate" during pulse laser alloying. Thickness of Mo coating $35 \mu \mathrm{m}$. Laser pulse energy $(d):(a)-5$; (b) -14.5 . 
size of focal zone, shielding gas flow rate, etc The amplitude-frequency analysis of the signal may bring useful information.

The simultaneous increase of laser power and BTS (keeping the ratio $P / V=$ const) leads to the decrease of weld seam width. Therefore, the sharp growth of surface temperature of melting pool was observed (Figure 3, curve 1). The conditions of welding were characterized by intensive boiling and evaporation that could induce the formation of porosity. The higher traverse speed at the same value of power allowed to minimize the size of weld seam (keeping the conditions of full penetration welding). In this case, the temperature was not extremely high (Figure 3 , curve 2).

3.3. CLADDING. Figure 4 illustrates the typical thermocycles for laser cladding measured at different distances from the centre of laser traverse. The maximum surface temperature of cladded layer reached Stellite- 6 melting point with a small overheating, and the cooling rate was nearly $1.7 \mathrm{kK} / \mathrm{s}$ (Figure 4, curves 1 ). The cooling rates in the centre of cladded zone (Figure 4, curve 1) and near its border (Figure 4, curve 2) are practically equal. These factors : small overheating, homogeneous temperature distribution and equal cooling rates indicate good quality of cladded layer. This statement is confirmed by examination of cladded layer which shows practically uniform microhardness (310-320 $H_{V}$ ), good adhesion, small $H A Z$ in the base material. In the heat affected zone the cooling rate is sharply decreased from $1.2 \mathrm{kK} / \mathrm{s}$ to $0.6 \mathrm{kK} / \mathrm{s}$ when the distance from the centre of laser traverse is increased from $1.6 \mathrm{~mm}$ to $1.8 \mathrm{~mm}$ (Figure 4 , curves 3 and 4 correspondingly). This is the main reason of base material micro hardness drop from 220 (cladded border) to $160 \mathrm{H}_{\mathrm{V}}$ (HAZ border).

3.4. PULSED ACTION. The samples of pure Fe with predeposited Mo coating were treated by pulsed laser radiation. The pulse duration was $4 \mathrm{~ms}$ and energy input range was 5-15 J. The pyrometer was aimed just into the centre of laser focus spot. The sudden temperature spike was observed during pulse laser action with $5 \mathrm{~J}$ energy (Figure 5-a). This spike corresponds to fast coating heating due to its nonideal thermal contact with substrate. In this case, coating was exfoliated from the surface and than was melted, partially evaporated and destroyed. The roller of solidified Mo was formed around the centre of laser focus spot. The temperature of uncovered substrate did not reach the iron melting point, so melting and alloying were absent. Increase of laser energy up to $9.5 \mathrm{~J}$ led to substrate melting after coating's destruction, as a result substrate was partially alloyed at the pulse end. The system coating-substrate was melted as a whole body when laser energy was equal to $14.5 \mathrm{~J}$. The temperature thermocycle looks like a classical temperature curve corresponding to pulsed laser action on a massive body except for the first stage (Figure 5b). First part of thermocycle was characterized, as before, by fast heating of Mo coating, but the surface of the substrate was melted before the Mo layer exfoliation and the temperature dropped due to the improvement of heat contact between Mo layer and Fe base. The second part of thermocycle corresponds to heating and melting of Mo-Fe system as a whole. A practically uniform distribution of doping element (Mo) in molten pool was found after laser alloying at pulse energy $14.5 \mathrm{~J}$. The pyrometric temperature measurements were confirmed by cross-section analysis of modified zone and by numerical simulation that have revealed qualitative different results versus energy per pulse : (a) coating's exfoliation and destruction without melting of substrate; (b) substrate's melting under the nondestroyed (but remelted) coating; (c) substrate's alloying from the coating (up to practically uniform remixing).

\section{REFERENCES}

1. Ignatiev M., Smurov I., Flamant G., Hernandez D. Performance of high speed pyrometer intended for real-time temperature measurements in laser machining. submitted to the Review of Scientific Instruments.

2. Ignatiev M., Ermolaev A., Titov V., Smurov I., Sturlese S., in Laser Treatment of Materials, ed by B.L. Mordike, Proceedings of ECLAT'92, pp. 15-20. 